Article

\title{
A Highly Selective and Strong Anti-Interference Host-Guest Complex as Fluorescent Probe for Detection of Amantadine by Indicator Displacement Assay
}

\author{
Linzhao Zhu, Zhiyong Zhao, Xiongzhi Zhang, Haijun Zhang, Feng Liang and Simin Liu * (10 \\ The State Key Laboratory of Refractories and Metallurgy, School of Chemistry and Chemical Engineering, \\ Wuhan University of Science and Technology, Wuhan 430081, China; zlz92400@163.com (L.Z.); \\ zhaozhiyong@wust.edu.cn (Z.Z.); zxz15872406033@163.com (X.Z.); zhanghaijun@wust.edu.cn (H.Z.); \\ feng_liang@wust.edu.cn (F.L.) \\ * Correspondence: liusimin@wust.edu.cn; Tel.: +86-27-6886-2338
}

Received: 24 March 2018; Accepted: 13 April 2018; Published: 19 April 2018

\begin{abstract}
Amantadine (AMA) and its derivatives are illicit veterinary drugs that are hard to detect at very low concentrations. Developing a fast, simple and highly sensitive method for the detection of AMA is highly in demand. Here, we designed an anthracyclic compound (ABAM) that binds to a cucurbit[7]uril (CB[7]) host with a high association constant of up to $8.7 \times 10^{8} \mathrm{M}^{-1}$. The host-guest complex was then used as a fluorescent probe for the detection of AMA. Competition by AMA for occupying the cavity of $\mathrm{CB}[7]$ allows ABAM to release from the CB[7]-ABAM complex, causing significant fluorescence quenching of ABAM (indicator displacement assay, IDA). The linear range of the method is from 0.000188 to $0.375 \mu \mathrm{g} / \mathrm{mL}$, and the detection limit can be as low as $6.5 \times 10^{-5} \mu \mathrm{g} / \mathrm{mL}(0.35 \mathrm{nM})$. Most importantly, due to the high binding affinity between CB[7] and ABAM, this fluorescence host-guest system shows great anti-interference capacity. Thus, we are able to accurately determine the concentration of AMA in various samples, including pharmaceutical formulations.
\end{abstract}

Keywords: fluorescent probe; amantadine; cucurbit[7]uril; host-guest interaction; indicator displacement assay

\section{Introduction}

Amantadine (AMA, Figure 1) was first found by Davies in 1964, and was used to treat influenza virus [1]. Because of its effective treatment and low cost, AMA was recognized as the first anti-influenza drug by the U.S. Food and Drug Administration (FDA) in 1966 [2,3]. With its advantages, AMA has been mixed with fodder, aiming to prevent and treat animal diseases, especially in chicken farming [4]. This kind of drug abuse results in the accumulation of AMA in the human body, causing various kinds of poisonous effects. Additionally, the abuse of AMA may also cause virus resistance and virus variation, which have bad effects on human treatment [5]. Because of these potential risks, AMA has been banned in livestock farming by USA and China since $2005[6,7]$. So far, lots of assays have been reported for the detection of AMA, including near-infrared spectroscopy [8,9], HPLC-MS/GC-MS [6,10-16], micellar electrokinetic chromatography (MEKC) [17], capillary electrophoresis $[18,19]$, and potentiometry $[20,21]$. However, those methods normally require complicated, expensive equipment and labor-intensive sample preparation procedures. Moreover, some of them are not sensitive enough. Spectrofluorimetry is regarded as one of the most convenient analytical techniques in pharmaceutical analysis, owing to its inherent simplicity, high sensitivity, and 
availability in most quality-controlled and clinical laboratories. Considering that the aqueous solution of AMA has no native fluorescence, the concentration of AMA cannot be directly determined through the normal fluorimetric method. Therefore, spectrofluorometric methods have been developed via the derivatization of AMA with a chromophore [22-24].

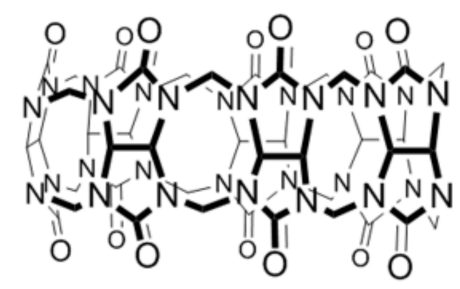

$\mathrm{CB}[7]$

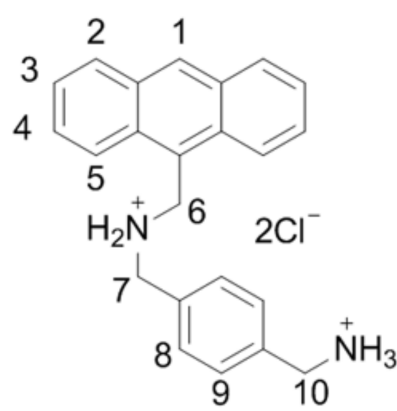

ABAM ( $\mathrm{HCl}$ salt)

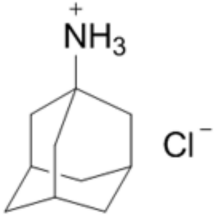

AMA ( $\mathrm{HCl}$ salt)

Figure 1. The structures of $\mathrm{CB}[7], \mathrm{ABAM}$, and AMA.

Cucurbit $[n]$ uril $(\mathrm{CB}[n], n=5-8,10,13-15)$ is a family of macrocyclic compounds with a hydrophobic cavity and $2 n$ carbonyl group on the portals [25-27]. As a novel synthetic host molecule, $\mathrm{CB}[n]$ shows its molecular recognition properties towards cationic and neutral guests with high selectivity and high affinity, and has been widely utilized in applications in nanoreactors/catalyst, supramolecular materials, and drug delivery/biomedicine [28-36]. CB[7] (Figure 1), one of the most studied members of the $\mathrm{CB}[n]$ family, shows its abilities to recognize a variety of guests with high association constant in aqueous solution, such as adamantylamine derivatives [37,38]. Due to the ability to alter the photophysical properties of fluorescent dyes [39], $\mathrm{CB}$ [7] has been applied to form a host-dye complex, which has been further used for determining analyte concentrations via indicator displacement assays (IDA) [40].

The first host-guest fluorescent probe system aiming at detecting AMA was reported in 2012 [41]. A natural isoquinoline alkaloid-coptisine (COP) was selected as the indicator, and the system was quite sensitive to AMA. Owing to the week binding interaction between $\mathrm{COP}$ and $\mathrm{CB}[7]$ $\left(K_{\mathrm{a}}=1.86 \times 10^{4} \mathrm{M}^{-1}\right)$, other non-target drug molecules may also displace COP from the complex and significantly skew measurement results. In another example, a bis-pyridine fluorescent molecule is used as the indicator [42]. But still, the binding interaction between the indicator and CB[7] is not strong enough $\left(K_{\mathrm{a}}=9.44 \times 10^{4} \mathrm{M}^{-1}\right)$. In order to achieve the detection of AMA with high selectivity, sensitivity, and anti-interference capacity, we designed a fluorescence indicator $\mathrm{N}$-(4-(aminomethyl)benzyl)-1-(anthracen-9-yl)methanamine (ABAM, Figure 1). We expect that aminomethyl-benzyl moiety could be encapsulated in CB[7] [37]; anthracene moiety could stay out of the cavity of $\mathrm{CB}[7]$ and its fluorescence signal could change upon complexation/decomplexation of ABAM with $\mathrm{CB}[7]$. Since the binding constants of $\mathrm{CB}$ [7]-xylylenediamine and $\mathrm{CB}$ [7]·AMA are $1.84 \times 10^{9} \mathrm{M}^{-1}$ and $4.2 \times 10^{12} \mathrm{M}^{-1}$, respectively [37], we expect the system could show high anti-interference capacity and maintain high sensitivity (Scheme 1). After making the new indicator, we investigated the binding behaviour of $\mathrm{ABAM}$ with $\mathrm{CB}$ [7], including the emission properties of ABAM upon encapsulation in $\mathrm{CB}[7]$, and plotted the standard curves upon the fluorescence change of CB[7]-ABAM system with addition of AMA. Finally, we determined the concentration of AMA in different samples, including mixture samples even pharmaceutical formulations. 


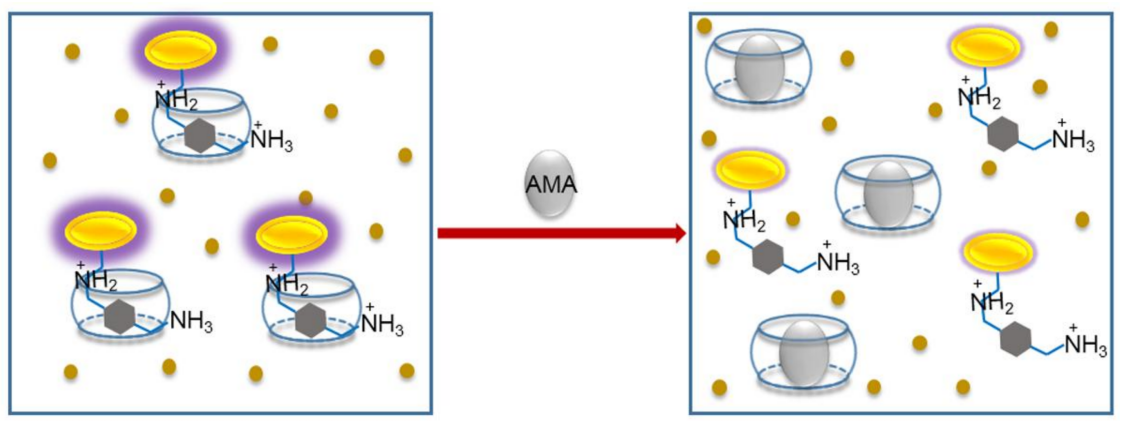

Scheme 1. Schematic representation of the principle of indicator displacement assay for the detection of AMA using the complex $\mathrm{CB}[7] \cdot \mathrm{ABAM}$ as a fluorescent probe.

\section{Results and Discussion}

\subsection{Binding Studies of the Fluorescent Indicator with CB[7]}

The fluorescence indicator $\mathrm{ABAM}$ (as $\mathrm{HCl}$ salt) was synthesized by the reaction of 9-(chloromethyl) anthracene with 1,4-di(aminomethyl) benzene (Scheme 2 in Section 3). The binding between ABAM (as $\mathrm{HCl}$ salt) and $\mathrm{CB}$ [7] was first investigated by ${ }^{1} \mathrm{H}$ NMR spectroscopy in $\mathrm{D}_{2} \mathrm{O}$ (Figure 2). As shown in Figure 2b, when the molar ratio between ABAM and CB[7] was 2:1, both free and bound peaks of ABAM molecule were observed, indicating the complexation-decomplexation processes between ABAM and $\mathrm{CB}[7]$ is slow exchange kinetics on the ${ }^{1} \mathrm{H}$ NMR time scale. The resonance signals of $\mathrm{H}_{8}, \mathrm{H}_{9}$, as well as $\mathrm{H}_{10}$ protons shifted upfield significantly $(\Delta \delta=0.79 \mathrm{ppm}, 0.96 \mathrm{ppm}$, and $0.42 \mathrm{ppm}$ respectively), suggesting the encapsulation of the 4-aminomethyl-benzyl moieties in the cavity of CB[7]. The signals of $\mathrm{H}_{5}$ and $\mathrm{H}_{6}$ protons shifted downfield significantly because of their location in the de-shielding region of $\mathrm{CB}[7]$. The slight downfield shifts of $\mathrm{H}_{1^{-4}}$ proton signals is caused by weakened $\pi-\pi$ stacking interactions between anthracene moieties upon the encapsulation of ABAM in $\mathrm{CB}$ [7] [43]. Adding more than 1 eq. of $\mathrm{CB}$ [7] did not induce further chemical shifts of ABAM proton signals, indicating the 1:1 host-guest complexation between the indicator and $\mathrm{CB}$ [7]. Based on this, a plausible schematic configuration of the inclusion complex CB[7].ABAM is given in Figure 2. Further, association constants of the $\mathrm{CB}[7] \cdot \mathrm{ABAM}$ complex as high as $8.7 \times 10^{8} \mathrm{M}^{-1}$ were obtained by ${ }^{1} \mathrm{H} \mathrm{NMR}$ competition experiment (Figure S4 and Table S1) [37].

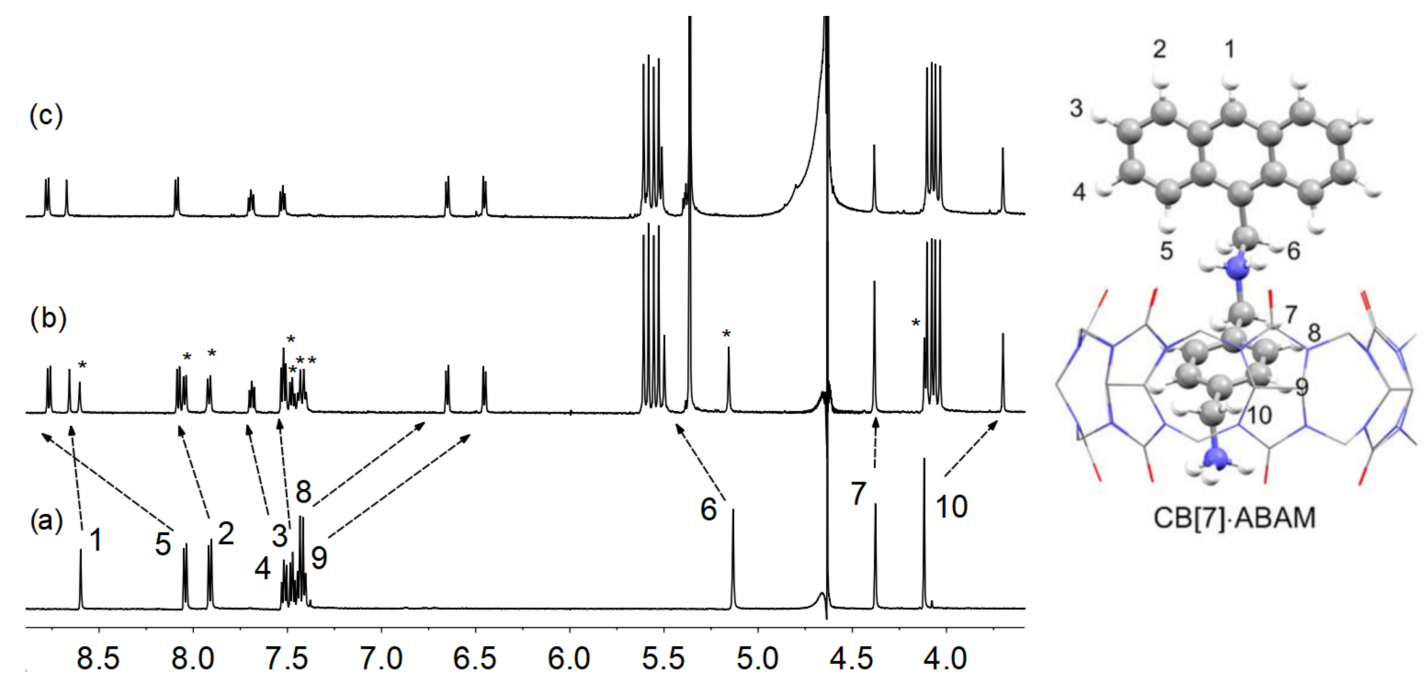

Figure 2. ${ }^{1} \mathrm{H}$ NMR spectra $\left(600 \mathrm{MHz}, \mathrm{D}_{2} \mathrm{O}, 298 \mathrm{~K}\right)$ of: (a) free ABAM (1.0 mM); (b) 2:1 mixture of ABAM and CB[7] (resonances of free ABAM are marked with *); (c) 1:1 mixture of ABAM and CB[7]. The plausible schematic configuration of the inclusion complex CB[7]·ABAM. 
Considering the $\mathrm{pH}$ value may have influence on fluorescence intensity changes in experiments, the $\mathrm{pH}$ value in all experiments for the detection of AMA was set as 4.70 using sodium acetate buffer (50 $\mathrm{mM})$. The fluorescence changes of the indicator in the presence of $\mathrm{CB}$ [7] host were investigated. As shown in Figure 3A, with addition of CB[7] to the ABAM solution, the fluorescence intensity of ABAM was significantly increased. As with most introduced $C B$ [7]-dye systems, the enhancement of fluorescence intensity of ABAM results from the dispersion of ABAM upon its inclusion in CB[7] [39]. Adding more than 1 eq. of $C B$ [7] could not change fluorescence much, verifying the stable 1:1 host-guest complex formation of ABAM with $\mathrm{CB}$ [7]. These results are in agreement with the NMR consequences. Considering that protonation/deprotonation could influence the emission of dye molecules, we recorded the fluorescence of ABAM and ABAM.CB[7] under various $\mathrm{pH}$ values. The results indicate that the acidities of $A B A M$ and $C B[7] \cdot A B A M$ are 8.8 and 11.5, respectively (Figure S5 and S6), which verifies that in the buffer $(\mathrm{pH} 4.70)$ the fluorescence changes of ABAM are completely irrelevant to the protonation/deprotonation of amino groups on ABAM. Additionally, the data proves the ability of $\mathrm{CB}$ [7] to increase the $\mathrm{p} K_{\mathrm{a}}$ value of the encapsulated guest molecule [44].

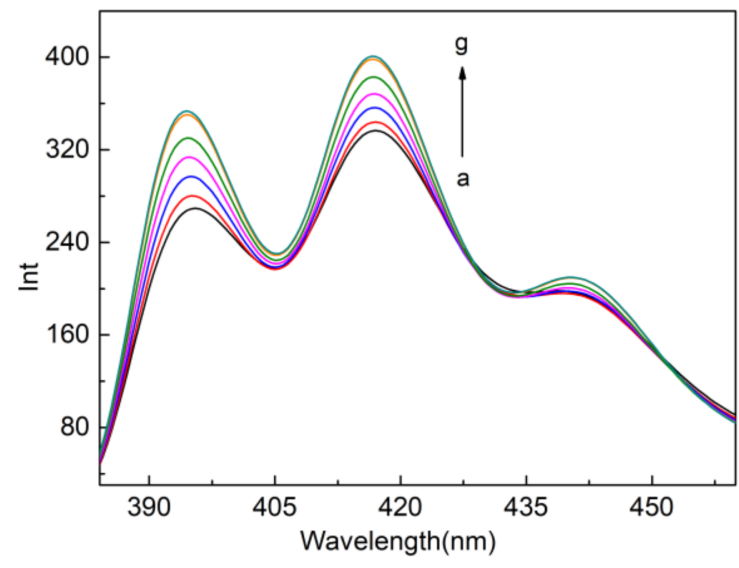

(A)

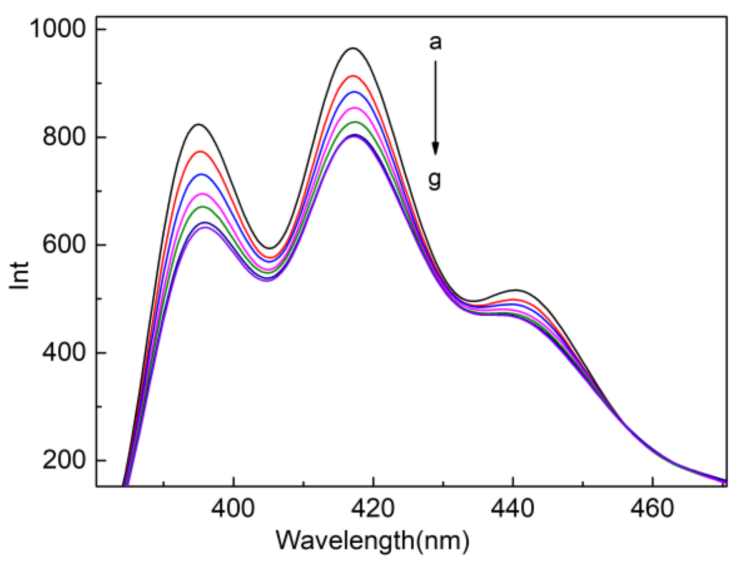

(B)

Figure 3. (A) Fluorescence spectra of the ABAM with addition of CB[7]: (a) 0; (b) 0.2 eq.; (c) 0.4 eq.; (d) 0.6 eq.; (e) 0.8 eq.; (f) 1.0 eq.; (g) 1.2 eq. ([ABAM] $=2 \mu \mathrm{M}, \mathrm{pH}=4.70, \lambda_{\mathrm{ex}} / \lambda_{\mathrm{em}}=366 / 417 \mathrm{~nm}$, the excitation and emission monochromator bandpasses were set at $15 \mathrm{~nm}$ and $3 \mathrm{~nm}$, respectively). (B) Fluorescence spectra of the ABAM in the presence of CB[7] with addition of AMA: (a) 0; (b) 0.2 eq.; (c) 0.4 eq.; (d) 0.6 eq.; (e) 0.8 eq.; (f) 1.0 eq.; (g) 1.2 eq. ([CB[7]·ABAM] $=0.2 \mu \mathrm{M}, \mathrm{pH}=4.70$, $\lambda_{\mathrm{ex}} / \lambda_{\mathrm{em}}=366 / 417 \mathrm{~nm}$, the excitation and emission monochromator bandpasses were set at $10 \mathrm{~nm}$ and $6 \mathrm{~nm}$, respectively).

\subsection{Plots of Standard Curve}

Since the binding constant of $\mathrm{CB}[7] \cdot \mathrm{AMA}$ is $~ 3.5$ order of magnitude higher than that of $\mathrm{CB}[7] \cdot \mathrm{ABAM}$, it is expected that AMA can easily displace ABAM from the complex CB[7]·ABAM. Indeed, adding AMA (as $\mathrm{HCl}$ salt) into the solution of $\mathrm{CB}[7] \cdot \mathrm{ABAM}$ complex caused an obvious decrease of fluorescence intensity of $C B$ [7]-ABAM system (Figure 3B). Similarly, after adding more than 1 eq. of AMA, the fluorescence intensity no longer decreased, because all of the indicator had been squeezed out of the cavity of $\mathrm{CB}$ [7]. Determining the proper concentration of the host-guest fluorescence system is crucial. If the concentration of probe system is too low, the sensitivity and accuracy could be low. Conversely, the high concentration may not help in determining the optimum detection limit of the analyte. After several attempts, we found the widest AMA detection range when the concentration of the host-guest probe system was $0.2 \mu \mathrm{M}$.

According to the changes of the fluorescence intensity of $\mathrm{CB}$ [7]-ABAM system as a function of the concentration of AMA, we plotted two standard curves for determining different ranges of AMA concentration (Figure 4) (the titration graphs are shown in Figures S7 and S8). When the concentrations 
of $\mathrm{CB}$ [7]-ABAM system are $2.0 \mu \mathrm{M}$ (Figure $4 \mathrm{~A}$ ) and $0.2 \mu \mathrm{M}$ (Figure $4 \mathrm{~B}$ ), the linear regression equations are $y=-221.47 x(\mu \mathrm{g} / \mathrm{mL})-1.32$ and $y=-5170.084 x(\mu \mathrm{g} / \mathrm{mL})-0.666$, respectively ( $y$ represents the change value of the fluorescence intensity, $x$ represents the mass concentration of AMA). The correlation coefficients of two equations are 0.998 and 0.999 , indicating good linearity. The linear ranges are $0.0375-0.375 \mu \mathrm{g} / \mathrm{mL}$ and $0.000188-0.0375 \mu \mathrm{g} / \mathrm{mL}$ for AMA, respectively. These equations can be directly used for the detection of AMA in real samples according to the change value of fluorescence intensity of $\mathrm{CB}$ [7]-ABAM system. With the detection limit as $6.5 \times 10^{-5} \mu \mathrm{g} / \mathrm{mL}$, this method proved to have higher sensitivity for detecting AMA than any other method reported in the literature (Table 1).

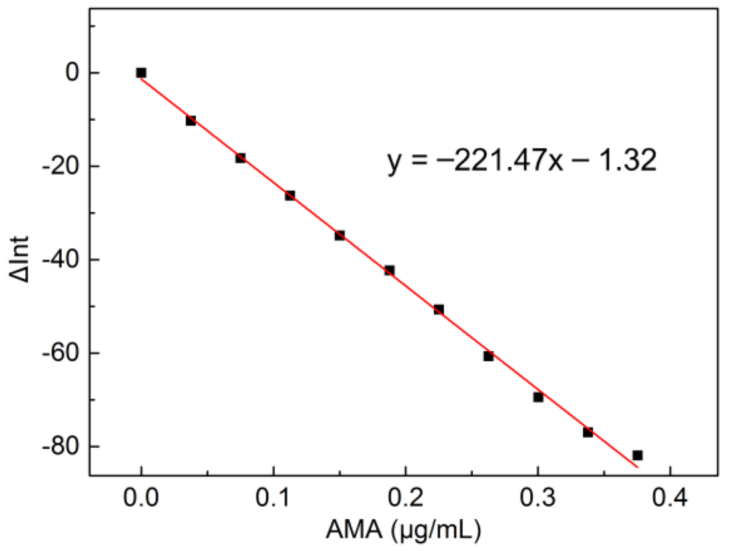

(A)

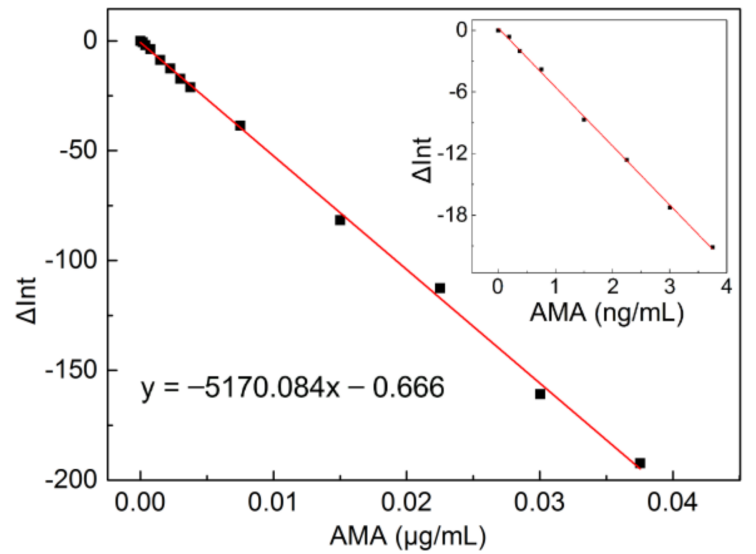

(B)

Figure 4. (A) The standard curve of AMA ranging from $0.0375 \mu \mathrm{g} / \mathrm{mL}-0.375 \mu \mathrm{g} / \mathrm{mL}$ $\left([\mathrm{CB}[7] \cdot \mathrm{ABAM}]=2.0 \mu \mathrm{M}, \mathrm{pH}=4.70, \lambda_{\mathrm{ex}} / \lambda_{\mathrm{em}}=366 / 417 \mathrm{~nm}\right)$. (B) The standard curve of AMA ranging from $0.000188 \mu \mathrm{g} / \mathrm{mL}-0.0375 \mu \mathrm{g} / \mathrm{mL}\left([\mathrm{CB}[7] \cdot \mathrm{ABAM}]=0.2 \mu \mathrm{M}, \mathrm{pH}=4.70, \lambda_{\mathrm{ex}} / \lambda_{\mathrm{em}}=366 / 417 \mathrm{~nm}\right)$.

Table 1. Various methods and detection limits for the detection of AMA.

\begin{tabular}{ccccc}
\hline Technique & Sample & $\begin{array}{c}\text { Linear Range } \\
(\mu \mathrm{g} / \mathbf{m L})\end{array}$ & $\begin{array}{c}\text { Minimum Working } \\
\text { Level }(\mu \mathrm{g} / \mathbf{m L})\end{array}$ & Refs \\
\hline HPLC & Biological samples & $0.025 \sim 2.5$ & 0.02 & {$[13]$} \\
LC-MS/MS & Rat plasma & $0.002 \sim 0.75$ & 0.002 & {$[14]$} \\
MEKC & human plasma & $0.002 \sim 0.06$ & 0.0005 & {$[17]$} \\
DLLME & urine & $0.0087 \sim 5$ & 0.0027 & {$[11]$} \\
potentiometry & blood-serum & $0.000118 \sim 0.013$ & $1.18 \times 10^{-4}$ & {$[21]$} \\
Spectrofluorimerty & Tabellae urine & $0.004 \sim 0.9$ & 0.0012 & {$[41]$} \\
Spectrofluorimerty & Tabellae & $0.000188 \sim 0.375$ & $6.5 \times 10^{-5}$ & This work ${ }^{1}$ \\
\hline \multicolumn{5}{c}{}
\end{tabular}

\subsection{Detection of AMA in Different Samples}

We firstly investigated the effect of interfering substances on this fluorescent probe system. Four different veterinary drugs-ribavirin, doxycycline, levofloxacin and florfenicol—were selected. From the fluorescence titration (Figure S9) we can see, after adding these interfering molecule mixtures to the host-guest probe system, that the fluorescence intensity didn't show any obvious change. Then, we tried to analyse the simulative samples. The four veterinary drugs mentioned above were mixed into the solution of AMA to simulate a real sample. Three simulated samples were prepared in which the concentrations of AMA were $150 \mathrm{nM}, 25 \mathrm{nM}$ and $5 \mathrm{nM}$, respectively. The concentration of each interfering molecule was 100 times higher than AMA, which means the total concentration of interfering substances was 400 times. A highly concentrated solution of the host-guest probe system in $50 \mathrm{mM} \mathrm{NaOAc}$ buffer was prepared, and then diluted to $0.2 \mu \mathrm{M}$ with the simulative sample. The fluorescence intensity values of the solution $\left(\mathrm{FI}_{\mathrm{CB}[7]-\mathrm{ABAM}-\mathrm{AMA}}\right)$ and the blank 
solution ( $\left.\mathrm{FI}_{\mathrm{CB}[7]-\mathrm{ABAM}}\right)$ were measured at $417 \mathrm{~nm}$ with an excitation wavelength of $366 \mathrm{~nm}$ (Figure $\mathrm{S10}$ ). Again, the change value of the fluorescence intensity $(\Delta \mathrm{FI})$ was put into the equation to calculate the concentration of AMA. In Table 2, the almost $100 \%$ recovery value indicates the system has strong anti-interference capacity, with high accuracy when the concentration of AMA in the sample was as low as $25 \mathrm{nM}(4.69 \mathrm{ng} / \mathrm{mL})$. Even when the concentration of AMA in the sample was as low as $5 \mathrm{nM}$ $(0.94 \mathrm{ng} / \mathrm{mL})$, a recovery value of $95 \%$ is good enough at such a low concentration. These results indicate that the fitting equations are very practical.

Table 2. Detecting result of simulative samples.

\begin{tabular}{cccc}
\hline Setting Concentration of AMA $(\mu \mathrm{g} / \mathrm{mL})$ & $\boldsymbol{\Delta}$ Int & Calculate Value $(\boldsymbol{\mu g} / \mathbf{m L})$ & Recovery $(\%) \pm$ S.D $^{\mathbf{1}}$ \\
\hline $0.0282(150 \mathrm{nM})$ & -144.06 & 0.028 & $99.3 \pm 0.34$ \\
$0.00469(25 \mathrm{nM})$ & -24.86 & 0.00468 & $99.8 \pm 0.78$ \\
$0.000939(5 \mathrm{nM})$ & -5.26 & 0.00089 & $94.8 \pm 1.09$ \\
\hline
\end{tabular}

${ }^{1}$ Average of five determinations; all measurements were performed in $50 \mathrm{mM} \mathrm{NaOAc}$ buffer $(\mathrm{pH}=4.70)$.

Furthermore, the real pharmaceutical formulation was tested. The amantadine hydrochloride tablet was obtained from Northeast Pharm. Each tablet contains: acetaminophen $250 \mathrm{mg}$, AMA hydrochloride $100 \mathrm{mg}$, artificial bezoar $10 \mathrm{mg}$, caffeine $15 \mathrm{mg}$, and chlorpheniramine maleate $2 \mathrm{mg}$. The other accessories include starch, magnesium stearate, hydroxypropyl cellulose. Weighed tablets were carefully pulverized, placed and sonicated with water in a $100 \mathrm{~mL}$ calibrated flask, and then the solution was filtered. AMA hydrochloride was regarded as undergoing no loss in the filtering operation, due to its good water solubility in buffer solution ( $\mathrm{pH} 4.70)$. The solution of AMA sample was further diluted to $100 \mathrm{nM}$, according to the AMA content per tablet in the drug instructions. The measuring operation was the same as that for the simulative samples. On the basis of this method, the detected concentration of AMA was $96.56 \mathrm{nM}$, and the recovery was up to $96.6 \%$ (Figure S11).

\section{Materials and Methods}

\subsection{Materials}

CB[7] was prepared according to the corresponding procedures in the literature [26]. Other compounds used in this study were purchased from commercial suppliers and used without further purification.

Synthesis of ABAM:
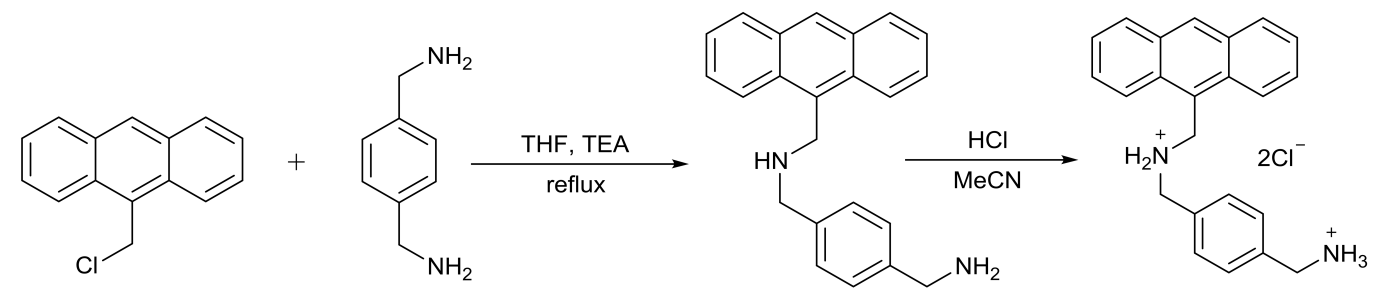

Scheme 2. Synthesis of fluorescence indicator ABAM (as $\mathrm{HCl}$ salt).

1,4-di(aminomethyl) benzene $(0.48 \mathrm{~g}, 3.53 \mathrm{mmol})$ and triethylamine $(0.45 \mathrm{~mL}, 3.11 \mathrm{mmol})$ were mixed in $30 \mathrm{~mL}$ dry THF in a flask, stirring at room temperature for an hour. After that, 9-(chloromethyl) anthracene $(0.40 \mathrm{~g}, 1.76 \mathrm{mmol})$ was added slowly to the solution, and the mixture was refluxed overnight. The mixture was filtered and evaporated to yield a yellow solid, which was purified by column chromatography with a 20:1 mixture of methylene dichloride/methanol. The product $\left(R_{\mathrm{f}}=0.34\right)$ was collected as a pale yellow solid-ABAM $(340 \mathrm{mg}, 60 \%)$. Dissolving the pure product into acetonitrile, bubbling hydrogen chloride gas in the solution, and then a white precipitate formed. 
The precipitate was collected and dried to give ABAM hydrochloride (390 mg, 94\%). ${ }^{1} \mathrm{H}$ NMR $(600 \mathrm{MHz}$ $\left.\mathrm{D}_{2} \mathrm{O}\right) \delta(\mathrm{ppm})=4.12\left(\mathrm{~s}, 2 \mathrm{H}, \mathrm{CH}_{2}\right), 4.38\left(\mathrm{~s}, 2 \mathrm{H}, \mathrm{CH}_{2}\right), 5.14\left(\mathrm{~s}, 2 \mathrm{H}, \mathrm{CH}_{2}\right), 7.42(\mathrm{~m}, 2 \mathrm{H}, \mathrm{CH}), 7.44(\mathrm{~d}, 2 \mathrm{H}, \mathrm{CH})$, $7.43(\mathrm{t}, 2 \mathrm{H}, \mathrm{CH}), 7.52(\mathrm{t}, 2 \mathrm{H}, \mathrm{CH}), 7.92(\mathrm{~d}, 2 \mathrm{H}, \mathrm{CH}), 8.05(\mathrm{~d}, 2 \mathrm{H}, \mathrm{CH}), 8.60(\mathrm{~s}, 1 \mathrm{H}, \mathrm{CH}) .{ }^{13} \mathrm{C} \mathrm{NMR}(150 \mathrm{MHz}$ $\left.\mathrm{D}_{2} \mathrm{O}\right) \delta(\mathrm{ppm})=134.18,130.94,130.84,130.27,130.03,129.67,129.46,129.18,127.35,125.27,121.78$, 119.78, 50.15, 42.59, 40.65. ESI-MS (positive ion): $m / z 327.19\left[\mathrm{ABAM}+\mathrm{H}^{+}\right]^{+}$(calcd. $\mathrm{C}_{23} \mathrm{H}_{23} \mathrm{~N}_{2}{ }^{+} 327.18$ ).

\subsection{Instrumentation}

NMR spectra $\left({ }^{1} \mathrm{H},{ }^{13} \mathrm{C}\right.$ and COSY) were collected on Agilent $600 \mathrm{MHz}$ DD2. Mass spectrometry was performed using a Bruker Agilent 1290-micrOTOF Q II. Fluorescence spectra were measured on a PerkinElmer LS-55 machine, with an excitation wavelength of $366 \mathrm{~nm}$.

\subsection{Determination of $K_{\text {rel }}$}

We use Equation 1 to determine $K_{\text {rel }}$ for the interaction of ABAM and $p$-xylylenediamine (PXDA) for $\mathrm{CB}$ [7]. For this purpose, we prepared a solution containing $\mathrm{CB}$ [7] (1.0 mM), ABAM (1.0 mM), PXDA (1.0 mM) and allowed it to reach equilibrium. Next, we determined the relative concentration of $\mathrm{CB}[7] \cdot A B A M$ by integration of the appropriate resonances in the ${ }^{1} \mathrm{H}$ NMR spectrum.

$$
\begin{gathered}
K_{\text {rel }}=\left([\mathrm{CB}[7] \cdot \mathrm{PXDA}][\mathrm{ABAM}]_{\text {free }}\right) /\left([\mathrm{CB}[7] \cdot \mathrm{ABAM}][\mathrm{PXDA}]_{\text {free }}\right) \\
{[\mathrm{PXDA}]_{\text {Total }}=1 \mathrm{mM}=[\mathrm{PXDA}]_{\text {free }}+[\mathrm{CB}[7] \cdot \mathrm{PXDA}]} \\
{[\mathrm{ABAM}]_{\text {Total }}=1 \mathrm{mM}=[\mathrm{ABAM}]_{\text {free }}+[\mathrm{CB}[7] \cdot \mathrm{ABAM}]} \\
{[\mathrm{CB}[7] \cdot \mathrm{PXDA}]=1-[\mathrm{CB}[7] \cdot \mathrm{ABAM}]}
\end{gathered}
$$

\section{Conclusions}

In summary, we have designed a new indicator compound ABAM bearing benzylamine unit as the binding group for $\mathrm{CB}$ [7] host and anthracene group as the chromophore. The high association constant of ABAM with $\mathrm{CB}$ [7] of up to $8.7 \times 10^{8} \mathrm{M}^{-1}$ suggests the strong anti-interference performance of the $\mathrm{CB}$ [7]-indicator system; the strong emission of the fluorescent probe at low concentration implies the low detection limit of the system. Indeed, through indicator displacement assay, we were able to fit the data to get nice linear equations, which could then be used in real sample detection. Further investigations revealed that as we expected, this system shows a low detection limit $\left(6.5 \times 10^{-5} \mu \mathrm{g} / \mathrm{mL}\right.$, the lowest detection limit ever reported) and strong anti-interference capacity. In combination with its easy synthesis and purification process, this system could be of great significance to the detection of AMA concentration in drugs and other samples, such as animal meats.

Supplementary Materials: The following are available online, Figures S1-S3: NMR spectrum of fluorescence indicator (ABAM hydrochloride); Figure S4: Competitive binding ${ }^{1} \mathrm{H}$ NMR spectrum; Table S1: Results of the determination of $K_{\text {rel }}$; Figures S5 and S6: The fluorescence intensity changes of ABAM and CB[7]·ABAM with different $\mathrm{pH}$; Figures S7 and S8: Fluorescence spectra recorded for CB[7]·ABAM with addition of AMA; Figure S9: Fluorescence spectra recorded for CB[7]. ABAM in the presence of interference sample; Figures S10 and S11: Fluorescence spectra recorded for CB[7]·ABAM for determining the concentration of AMA in samples.

Acknowledgments: This work was financially supported by the National Natural Science Foundation of China (Nos. 21472143, 21604066 and 21372183), the Thousand Youth Talents Program of China, and Program for Innovative Teams of Outstanding Young and Middle-aged Researchers in the Higher Education Institutions of Hubei Province (No. T201602).

Author Contributions: F.L. and S.L. conceived and designed the experiments; L.Z. performed the experiments; L.Z. and Z.Z. and X.Z. analysed the data; H.Z. contributed reagents/materials/analysis tools; L.Z. and S.L. wrote the paper.

Conflicts of Interest: The authors declare no conflict of interest. 


\section{References}

1. Davies, W.L.; Grunert, R.R.; Haff, R.F.; Mcgahen, J.W.; Neumayer, E.M.; Paulshock, M.; Watts, J.C.; Wood, T.R.; Hermann, E.C.; Hoffmann, C.E. Antiviral activity of 1-adamantanamine (amantadine). Science 1964, 144, 862-863. [CrossRef] [PubMed]

2. Oxford, J.S.; Galbraith, A. Antiviral activity of amantadine: a review of laboratory and clinical data. Pharmacol. Ther. 1980, 11, 181-262. [CrossRef]

3. Dobrovolny, H.M.; Gieschke, R.; Davies, B.E.; Jumbe, N.L.; Beauchemin, C.A. Neuraminidase inhibitors for treatment of human and avian strain influenza: A comparative modeling study. J. Theor. Biol. 2011, 269, 234-244. [CrossRef] [PubMed]

4. Dal, P.F.; Thiry, E. Antiviral chemotherapy in veterinary medicine: current applications and perspectives. Rev. Sci. Tech. 2014, 33, 791-801.

5. Hayden, F.G. Antivirals for influenza: Historical perspectives and lessons learned. Antivir. Res. 2006, 71, 372-378. [CrossRef] [PubMed]

6. Chan, D.; Tarbin, J.; Sharman, M.; Carson, M.; Smith, M.; Smith, S. Screening method for the analysis of antiviral drugs in poultry tissues using zwitterionic hydrophilic interaction liquid chromatography/tandem mass spectrometry. Anal. Chim. Acta 2011, 700, 194-200. [CrossRef] [PubMed]

7. He, G.; Qiao, J.; Dong, C.; He, C.; Zhao, L.; Tian, Y. Amantadine resistance among H5N1 avian influenza viruses isolated in Northern China. Antivir. Res. 2008, 77, 72-76. [CrossRef] [PubMed]

8. Dou, Y.; Sun, Y.; Ren, Y.; Ju, P.; Ren, Y. Simultaneous non-destructive determination of two components of combined paracetamol and amantadine hydrochloride in tablets and powder by NIR spectroscopy and artificial neural networks. J. Pharm. Biomed. 2005, 37, 543-549. [CrossRef] [PubMed]

9. Titova, A.V.; Arzamastsev, A.P.; Gretskii, S.V. Analysis of rimantadine hydrochloride by near-infrared spectroscopy. Pharm. Chem. J. 2009, 43, 534-537. [CrossRef]

10. Tsuruoka, Y.; Nakajima, T.; Kanda, M.; Hayashi, H.; Matsushima, Y.; Yoshikawa, S.; Nagata, M.; Koike, H.; Nagano, C.; Sekimura, K.; et al. Simultaneous determination of amantadine, rimantadine, andmemantine in processed products, chicken tissues, and eggs by liquidchromatography with tandem mass spectrometry. J. Chromatogr. B 2017, 1044-1045, 142-148. [CrossRef] [PubMed]

11. Farajzadeh, M.A.; Nouri, N.; Nabil, A.A.A. Determination of amantadine in biological fluids using simultaneousderivatization and dispersive liquid-liquid microextraction followedby gas chromatographyflame ionization detection. J. Chromatog. B 2013, 940, 142-149. [CrossRef] [PubMed]

12. Duh, T.H.; Wu, H.L.; Pan, C.W.; Kou, H.S. Fluorimetric liquid chromatographic analysis of amantadine in urine and pharmaceutical formulation. J. Chromatogr. A 2005, 1088, 175-181. [CrossRef] [PubMed]

13. Higashi, Y.; Nakamura, S.; Matsumura, H.; Fujii, Y. Simultaneous liquid chromatographic assay of amantadine and its four related compounds in phosphate-buffered saline using 4-fluoro-7-nitro-2,1,3benzoxadiazole as a fluorescent derivatization reagent. Biomed. Chromatogr. 2006, 20, 423-428. [CrossRef] [PubMed]

14. Xu, M.; Ju, W.; Xia, X.; Tan, H.; Chen, M.; Zhang, J.; Xiong, N.; Jiang, M.; Chen, L.; Gong, L. Determination of rimantadine in rat plasma by liquid chromatography/electrospray mass spectrometry and its application in a pharmacokinetic study. J. Chromatogr. B 2008, 864, 123-128. [CrossRef] [PubMed]

15. Cui, S.J.; Fang, F.; Han, L.; Ming, M. New method for high-performance liquid chromatographic determination of amantadine and its analogues in rat plasma. J. Pharm. Biomed. 2007, 44, 1100-1105.

16. Askal, H.F.; Khedr, A.S.; Darwish, I.A.; Mahmoud, R.M. Quantitative thin-layer chromatographic method for determination of amantadine hydrochloride. Int. J. Biomed. Sci. 2008, 4, 155-160. [PubMed]

17. Yeh, H.H.; Yang, Y.H.; Chen, S.H. Simultaneous determination of memantine and amantadine in human plasma as fluorescein derivatives by micellar electrokinetic chromatography with laser-induced fluorescence detection and its clinical application. Electrophoresis 2010, 31, 1903-1911. [CrossRef] [PubMed]

18. Pazourek, J.; Revilla, A.L.; Gajdosová, D.; Havel, J. Validation of a capillary zone electrophoresis method for determination of rimantadine hydrochloride in rimantadin100 Tablets and the method application to dissolution test monitoring. Drug. Dev. Ind. Pharm. 2004, 30, 125-134. [CrossRef] [PubMed]

19. Reichová, N.; Pazourek, J.; Polásková, P.; Havel, J. Electrophoretic behavior of adamantane derivatives possessing antiviral activity and their determination by capillary zone electrophoresis with indirect detection. Electrophoresis 2002, 23, 259-262. [CrossRef] 
20. Abdel-Ghani, N.T.; Shoukry, A.F.; Hussein, S.H. Flow injection potentiometric determination of amantadine HCl. J. Pharm. Biomed. 2002, 30, 601-611. [CrossRef]

21. Jalali, F.; Maghooli, R. Potentiometric Determination of trace amounts of amantadine using a modified carbon-paste electrode. Anal. Sci. 2009, 25, 1227-1230. [CrossRef] [PubMed]

22. Mahmoud, A.M.; Khalil, N.Y.; Darwish, I.A.; Aboul-Fadl, T. Selective spectrophotometric and spectrofluorometric methods for the determination of amantadine hydrochloride in capsules and plasma via derivatization with 1,2-Naphthoquinone-4-sulphonate. Int. J. Anal. Chem. 2009, 2009, 1-8. [CrossRef] [PubMed]

23. Darwish, I.A.; Khedr, A.S.; Askal, H.F.; Mahmoud, R.M. Simple fluorimetric method for determination of certain antiviral drugs via their oxidation with cerium (IV). Rev. Bras. Farmacogn. 2005, 60, 555-562. [CrossRef] [PubMed]

24. Mustafa, A.A.; Abdel-Fattah, S.A.; Toubar, S.S.; Sultan, M.A. Spectrophotometric determination of acyclovir and amantadine hydrochloride through metals complexation. J. Anal. Chem. 2004, 59, 33-38. [CrossRef]

25. Kim, J.; Jung, I.S.; Kim, S.Y.; Lee, E.; Kang, J.K.; Sakamoto, S.; Yamaguchi, K.; Kim, K. New Cucurbituril Homologues: Syntheses, Isolation, Characterization, and X-ray Crystal Structures of Cucurbit $[n]$ uril $(n=5,7$, and 8). J. Am. Chem. Soc. 2000, 122, 540-541. [CrossRef]

26. Day, A.; Arnold, A.P.; Blanch, R.J.; Snushall, B. Controlling factors in the synthesis of cucurbituril and its homologues. J. Org. Chem. 2001, 66, 8094-8100. [CrossRef] [PubMed]

27. Li, Q.; Qiu, S.C.; Zhang, J.; Chen, K.; Huang, Y.; Xiao, X.; Zhang, Y.; Li, F.; Zhang, Y.Q.; Xue, S.F.; et al. Twisted Cucurbit[n]urils. Org. Lett. 2016, 18, 4020-4023. [CrossRef] [PubMed]

28. Lagona, J.; Mukhopadhyay, P.; Chakrabarti, S.; Isaacs, L. The Cucurbit[n]uril Family. Angew. Chem. Int. Ed. 2005, 44, 4844-4870. [CrossRef] [PubMed]

29. Masson, E.; Ling, X.; Joseph, R.; Kyeremeh, M.L.; Lu, X. Cucurbituril chemistry: A tale of supramolecular success. RSC Adv. 2012, 2, 1213-1247. [CrossRef]

30. Assaf, K.I.; Nau, W.M. Cucurbiturils: from synthesis to high-affinity binding and catalysis. Chem. Soc. Rev. 2015, 44, 394-418. [CrossRef] [PubMed]

31. Barrow, S.J.; Kasera, S.; Rowland, M.J.; Barrio, J.D.; Scherman, O.A. Cucurbituril-Based Molecular Recognition. Chem. Rev. 2015, 115, 12320-12406. [CrossRef] [PubMed]

32. Shetty, D.; Khedkar, J.K.; Park, K.M.; Kim, K. Can we beat the biotin-avidin pair? cucurbit[7]uril-based ultrahigh affinity host-guest complexes and their applications. Chem. Soc. Rev. 2015, 44, 8747-8761. [CrossRef] [PubMed]

33. Tian, J.; Wang, H.; Zhang, D.; Liu, Y.; Li, Z. Supramolecular organic frameworks (SOFs): Homogeneous regular 2D and 3D pores in water. Natl. Sci. Rev. 2017, 4, 426-436. [CrossRef]

34. Gao, R.H.; Chen, L.X.; Chen, K.; Tao, Z.; Xiao, X. Development of hydroxylated cucurbit $[n]$ urils, their derivatives and potential applications. Coord. Chem. Rev. 2017, 348, 1-24. [CrossRef]

35. Kuok, K.I.; Li, S.; Wyman, I.W.; Wang, R. Cucurbit[7]uril: An emerging candidate for pharmaceutical excipients. Ann. N.Y. Acad. Sci. 2017, 1398, 108-119. [CrossRef] [PubMed]

36. Yang, X.; Liu, F.; Zhao, Z.; Liang, F.; Zhang, H.; Liu, S. Cucurbit[10]uril-based chemistry. Chin. Chem. Lett. 2018. [CrossRef]

37. Liu, S.; Ruspic, C.; Mukhopadhyay, P.; Chakrabarti, S.; Zavalij, P.Y.; Isaacs, L. The cucurbit[n]uril family: Prime components for self-sorting systems. J. Am. Chem. Soc. 2005, 127, 15959-15967. [CrossRef] [PubMed]

38. Moghaddam, S.; Yang, C.; Rekharsky, M.; Ko, Y.H.; Kim, K.; Inoue, Y.; Gilson, M.K. New ultrahigh affinity host-guest complexes of cucurbit[7]uril with bicyclo[2.2.2]octane and adamantane guests: Thermodynamic analysis and evaluation of M2 affinity calculations. J. Am. Chem. Soc. 2011, 133, 3570-3581. [CrossRef] [PubMed]

39. Dsouza, R.N.; Pischel, U.; Nau, W.M. Fluorescent dyes and their supramolecular host/guest complexes with macrocycles in aqueous solution. Chem. Rev. 2011, 111, 7941-7980. [CrossRef] [PubMed]

40. Ghale, G.; Nau, W.M. Dynamically analyte-responsive macrocyclic host-fluorophore systems. Acc. Chem. Res. 2014, 47, 2150-2159. [CrossRef] [PubMed]

41. Wang, G.Q.; Qin, Y.F.; Du, L.M.; Li, J.F.; Jing, X.; Chang, Y.X.; Wu, H. Determination of amantadine and rimantadine using a sensitive fluorescent probe. Spectrochem. Acta A 2012, 98, 275-281. [CrossRef] [PubMed] 
42. Yang, H.; Liu, Y.L.; Yang, L.L.; Liu, K.; Wang, Z.Q.; Zhang, X. Cucurbit[7]uril as a "protective agent": Controlling photochemistry and detecting 1-adamantanamine. Chem. Commun. 2013, 49, 3905-3907. [CrossRef] [PubMed]

43. Kuang, S.; Hu, Z.; Zhang, H.; Zhang, X.; Liang, F.; Zhao, Z.; Liu, S. Enhancement of metal-metal interactions inside a large-cavity synthetic host in water. Chem. Commun. 2018, 54, 2169-2172. [CrossRef] [PubMed]

44. Ghosh, I.; Nau, W.M. The strategic use of supramolecular $\mathrm{p} K_{\mathrm{a}}$ shifts to enhance the bioavailability of drugs. Adv. Drug. Deliv. Rev. 2012, 64, 764-783. [CrossRef] [PubMed]

Sample Availability: Samples of the compounds ABAM and CB[7] are available from the authors.

(C) 2018 by the authors. Licensee MDPI, Basel, Switzerland. This article is an open access article distributed under the terms and conditions of the Creative Commons Attribution (CC BY) license (http:/ / creativecommons.org/licenses/by/4.0/). 